OPEN ACCESS

Edited by:

Heiko Mühl,

Goethe University Frankfurt,

Germany

Reviewed by:

Dechun Feng,

National Institute on Alcohol

Abuse and Alcoholism,

United States

Tobias Andreas Beyer,

ETH Zurich, Switzerland

*Correspondence:

Yiqiang Wang

yiqiangwang@suda.edu.cn

Specialty section:

This article was submitted

to Inflammation, a

section of the journal

Frontiers in Immunology

Received: 25 December 2017

Accepted: 28 March 2018

Published: 18 April 2018

Citation:

Lin D, Sun Z, Jin Z, Lei L, Liu Y,

$H u B$, Wang $B$, Shen $Y$ and Wang $Y$ (2018) Matrix Remodeling Associated 7 Deficiency Alleviates

Carbon Tetrachloride-Induced

Acute Liver Injury in Mice.

Front. Immunol. 9:773.

doi: 10.3389/fimmu.2018.00773

\section{Matrix Remodeling Associated 7 Deficiency Alleviates Carbon Tetrachloride-Induced Acute Liver Injury in Mice}

\author{
Dandan Lin', Zhenjiang Sun', Ziqi Jin², Lei Lei², Yonghao Liü2, Bo Hu², Benfang Wang1, \\ Ying Shen ${ }^{1}$ and Yiqiang Wang ${ }^{1 *}$
}

${ }^{1}$ Key Laboratory of Thrombosis and Hemostasis Ministry of Health, Collaborative Innovation Center of Hematology, Jiangsu Institute of Hematology, The First Affiliated Hospital of Soochow University, Medical College, Soochow University, Suzhou, China, ${ }^{2}$ Department of Hematology, Institute of Hematopoietic Stem Cell Transplantation, Collaborative Innovation Center of Hematology, The First Affiliated Hospital of Soochow University, Medical College, Soochow University, Suzhou, China

Matrix remodeling associated 7 (MXRA7) was first noted to co-express with a group of matrix remodeling related genes, and its biological functions had remained unclear. In this study, we investigated the presumed function of MXRA7 in a carbon tetrachloride $\left(\mathrm{CCl}_{4}\right)$-induced acute liver injury model in mice. Wild-type, MXRA7-/- mice, and mice that were pulsed with hydrodynamic injection of vehicle or MXRA7-harboring plasmids were challenged with a single dose of $\mathrm{CCl}_{4}$ for injury induction. The sera, spleens, and livers were harvested from mice for assay of cytokines/chemokines expression, cellular responses, or histological features. We found that MXRA7 deficiency alleviated, and MXRA7 overexpression aggravated liver damage in $\mathrm{CCl}_{4}$-challenged mice. FACS analysis showed that MXRA7 deficiency reduced the recruitment of neutrophils through downregulation the expression of CXCL1 and CXCL2 in liver, decreased the number of $\mathrm{CD}^{+} \mathrm{T}$ cells in liver and spleen, suppressed the release of IFN $\gamma$ and TNF $\alpha$ from T cells, and decreased IFN $\gamma$ in serum and liver. Western blot assay demonstrated that MXRA7 deficiency suppressed the activation of MAPK pathway and AKT/NF-kB pathway, respectively. Lastly, MXRA7 deficiency or overexpression regulated the expression of two matrix remodeling-related genes (fibronectin and TIMP1) in the liver. We concluded that MXRA7 was an active player in $\mathrm{CCl}_{4}$-induced liver injury, hypothetically by mediating the inflammation or immune compartments and matrix remodeling processes. Further exploration of MXRA7 as a possible new therapeutic target for management of inflammationmediated liver injury was discussed.

Keywords: matrix remodeling associated 7, acute liver injury, neutrophils, extracellular matrix, pro-inflammatory cytokines

\section{INTRODUCTION}

Liver is a vital organ which performs important functions like extensive synthesis, retinoid storage, metabolism, detoxification, secretion of proteins, etc. $(1,2)$. Liver diseases are one panel of the endangering problems which lead to mortality and morbidity over the world $(3,4)$. Liver injuries or diseases can be caused by many factors, including drugs, toxins, alcohol, and virus infection $(5,6)$. Acute liver injury (ALI) occurs within a short period and is a common pathway to many liver diseases. The pathogenesis of ALI involves oxidative stress, hepatocyte apoptosis and necrosis, 
immune responses, etc. (6-8). ALI also involves inflammation and may progress to chronic liver injury, hepatic fibrosis, or even hepatocellular carcinoma (9). Therefore, searching for new therapeutic options for treatment of liver injury is critical for handling liver diseases in clinical practice.

In laboratory studies concerning liver injury, carbon tetrachloride $\left(\mathrm{CCl}_{4}\right)$ is commonly used as a chemical toxin to induce ALI model in mice (10). $\mathrm{CCl}_{4}$ is metabolized by cytochrome $\mathrm{P} 450$ (CYP2E1) in liver to form trichloromethyl and trichloromethyl peroxy radicals, which in turn induce oxidative stress, lipid peroxidation, and hepatic injury (11). Except for oxidative stress, inflammation is another important mechanism mediating $\mathrm{CCl}_{4^{-}}$ induced liver injury $(12,13)$. In this process, pro-inflammatory cytokines and chemokines are crucial players that incur cell death and liver injury (14-16). Correspondingly, previous studies suggested that the liver injury can be prevented by suppressing oxidative stress and inflammation $(17,18)$. Therefore, metabolism and inflammatory response are thought to be therapy targets in the treatment of liver injury. On the other side, liver injury and recovery also involve matrix remodeling, a process that underlies structural changes occurred in any tissues, including liver $(19,20)$. Thus, dissecting the relationship between matrix remodeling and liver injury also provides new possibilities for developing novel therapy of liver injury. In a previous study, we sighted expression of a novel gene, matrix remodeling associated 7 (MXRA7), in liver at mRNA level (21), but its possible involvement in any physiological or pathological processes of liver had not been addressed in any study. MXRA7, first named in a bioinformatics study in 2002, belongs to the MXRA family consisting of eight genes (MXRA1MXRA8) possibly involved in cell adhesion and matrix remodeling (22). Studies have reported that some members of this family are related with a variety of critical physiological and pathological processes, such as MXRA2 in matrix degradation (23), MXRA3 in actin polymerization and cell motility (24), MXRA5 in antiinflammatory and anti-fibrotic responses (25), and MXRA6 in myofibroblast differentiation and extracellular matrix formation (26). However, the function of MXRA7 has been barely investigated except for our previous study showing a dynamic change of MXRA7 mRNA in inflammatory corneal diseases models in adult mice (21).

In the present study, we used mice genetically deficient of MXRA7 (MXRA7 ${ }^{-/-}$) or artificially overexpressing MXRA7 to investigate the hypothetical role of MXRA7 in $\mathrm{CCl}_{4}$-induced ALI in mice. The levels of serum alanine aminotransferase (ALT) and aspartate aminotransferase (AST) and histopathological analysis were used to evaluate liver functions. The inflammatory response and pro-inflammatory cytokines as well as extracellular matrix molecules were measured to elucidate the underlying mechanism. Our findings indicated an important role of MXRA7 in liver injury in vivo.

\section{MATERIALS AND METHODS}

\section{Animals}

Heterozygous MXRA7-deficient (MXRA7 ${ }^{+-}$) mice of both sexes on $\mathrm{C} 57 \mathrm{BL} / 6 \mathrm{~N}$ background were purchased from the Medical Research Council (MRC, Swindon, UK). The MXRA7 $^{-1-}$ and wild-type (WT) breeders were generated by cross-breeding female and male $\mathrm{MXRA} 7^{+/-}$mice, and genotyped according to the protocol provided by MRC (Figure S1 in Supplementary Material). The breeders were used for generating WT and MXRA7 ${ }^{-1-}$ colonies, respectively. The male mice of WT and $\mathrm{MXRA}^{-1-}$ (aged 6-8 weeks) were used in the study. Specific pathogen-free male C57BL/6N mice (aged 6-8 weeks) were obtained from Nanjing Biomedical Research Institute of Nanjing University (Nanjing, China). All mice were housed in specific pathogen-free facility in Soochow University.

\section{MXRA7-Delivery Plasmid Construction and Hydrodynamic Gene Transfer (HGT) In Vivo}

The murine MXRA7 cDNA was cloned from splenocytes of mouse and inserted into a minicircle (MC) plasmid (pMC.EF1, System Biosciences, Mountain View, CA, USA) to construct the MXRA7-delivery plasmid (pMC-MXRA7), while the mock pMC.EF1 plasmid was used as control plasmid in the study. Confirmation with sequencing, preparation, and purification of both plasmids were performed as previously described (27). pMC plasmids were delivered into mice by HGT technique $(80 \mu \mathrm{g}$ plasmids in $2.5 \mathrm{ml}$ PBS/mouse). Three days postinjection of plasmids, the mice were subjected to ALI induction as described below.

\section{Acute Liver Injury}

The animal experiments were divided into two sections, namely, the MXRA7 deficiency section using WT and MXRA7 ${ }^{-1-}$ mice, and the MXRA7 overexpression section using mice challenged with pMC.EF1 (control) or pMC-MXRA7 plasmids. $\mathrm{CCl}_{4}$ (Sinopharm, Shanghai, China) was used to induce liver injury of differently severity in mice. For survival experiments, the mice were injected intraperitoneally (i.p.) with $6 \mathrm{ml} / \mathrm{kg}$ body weight $\mathrm{CCl}_{4}$ (1:1 dilution in corn oil) and the survival of mice were observed every day. Pilot experiments and previous studies had determined this lethal dose within 1 week in WT mice to be around $6 \mathrm{ml} / \mathrm{kg}$ body weight $\mathrm{CCl}_{4}$ (1:1 corn oil) (27). For short-term ALI induction and acute phase assay, the mice were injected i.p. with a dose of $1 \mathrm{ml} / \mathrm{kg} \mathrm{CCl}$ (1:1 dilution in corn oil). The mice were sacrificed $24 \mathrm{~h}$ after $\mathrm{CCl}_{4}$ administration. Blood, spleen, and liver samples were collected for further analysis as following.

\section{Analysis of Serum Aspartate Aminotransferase and Alanine Aminotransferase Activity}

The blood samples were collected and centrifuged to separate the serum. The activity of serum ALT and AST were determined by commercial reagent kit (AILEX, Shanghai, China) with a Hitachi 7600 automatic biochemical analyzer (Hitachi, Tokyo, Japan) according to the manufacturer's protocol.

\section{Histopathological Analysis}

The liver tissues from different groups of mice were fixed with $10 \%$ neutral buffered formalin and then embedded in paraffin. Paraffin-embedded tissues were cut into $5 \mu \mathrm{m}$ thick sections and stained with hematoxylin and eosin for histopathological 
examination through a light microscope (Nikon, Tokyo, Japan). The percentage of necrotic area was determined by measuring the necrotic area relative to the entire liver area using Image J software (vision1.49, NIH, Bethesda, MD, USA) as described earlier (8).

\section{Flow Cytometry Analysis}

Single cell suspensions prepared from spleen and liver were analyzed using flow cytometry (FACS) (28). The antibodies used for FACS staining including anti-mouse CD3-PE or CD3-FITC, CD4PerCP/Cy5.5 or CD4-FITC, CD8-APC or CD8-FITC, CD69FITC, CD62L-PerCP/Cy5.5, CD44-PE, CD19-APC, NK1.1-PE or NK1.1-PerCP/Cy5.5, Ly6C/Ly6G-Gr1, F4/80-PerCP/Cy5.5, IFN $\gamma$-PE, and TNF $\alpha$-APC were purchased from Biolegend (San Diego, CA, USA). Anti-mouse CD16/32 FcR blocking antibody was also from Biolegend. For intracellular cytokine staining, cells were stimulated with $50 \mathrm{ng} / \mathrm{ml}$ phorbol 12-myristate 13 -acetate (PMA, Beyotime, Haimen, China) and $500 \mathrm{ng} / \mathrm{ml}$ ionomycin (Beyotime) for $4 \mathrm{~h}$ in the presence of $1 \times$ brefeldin $\mathrm{A}$ (Biolegend). Cells were harvested and stained with surface antibodies, then were washed, fixed with $4 \%$ paraformaldehyde, permeabilized with $1 \%$ saponin and stained with intracellular cytokine antibodies. FACS was performed using a FACS Calibur flow cytometer (BD Biosciences, San Jose, CA, USA) and analyzed using Flowjo software (Tree Star, Ashland, OR, USA).

\section{Cytokine Analysis}

Serum cytokine levels were analyzed using BD cytometric bead array (CBA) mouse inflammation kit (BD Pharmingen, San Diego, CA, USA) on a FACS Calibur Cytometer and analyzed using BD FCAP Array software (BD Bioscience). The cytokine kit covered mouse IL-6, IL-10, IL-12p70, TNF, IFN $\gamma$, and MCP-1.

\section{Reverse Transcription-Quantitative Real- Time PCR (RT-qPCR)}

The total RNA was extracted from liver tissues with RNAiso plus reagent (TaKaRa, Dalian, China), and reverse-transcribed into cDNA with reverse transcriptase M-MLV reagent (TaKaRa, Dalian, China) according to manufacturer's instructions. Quantitative real-time PCR (qPCR) was performed using SYBR Premix Ex Taq reagent (TaKaRa, Dalian, China) and carried out on a QuantStudio 3 real-time PCR system (Applied Biosystems, Foster City, CA, USA). The primer sequences used in the experiment were listed in supplementary Table S1 in Supplementary Material and the primers were synthesized by Genewiz Company (Suzhou, China). The $\beta$-actin gene was used as an internal control and the data were analyzed using $2^{-\Delta \Delta C t}$ method.

\section{Immunofluorescence Staining}

The sections of liver tissues were blocked with 3\% BSA in PBS for $1 \mathrm{~h}$ at room temperature, and then incubated with primary antibodies overnight at $4^{\circ} \mathrm{C}$. The primary antibodies were antiLy6C/Ly6G antibody (Bio X Cell, West Lebanon, NH), anti-F4/80 antibody (Abcam, Cambridge, MA, USA) and anti-fibronectin antibody (Abcam). After washing in PBS for three times, the sections were incubated with Alexa Fluor 555 anti-rat IgG antibody or Alexa Fluor 488 anti-rabbit IgG antibody (Abcam) at room temperature for $1 \mathrm{~h}$ in the dark. After counterstaining with DAPI (Beyotime), the sections were observed and photographed with a Leica TCS SP8 Confocal Microscope (Buffalo Grove, IL, USA).

\section{TUNEL Staining}

To evaluate apoptosis of hepatocytes in liver tissues, paraffinembedded sections were stained by using a One Step TUNEL Apoptosis Assay Kit (Beyotime) according to the manufacturer's instructions. Sections were counterstained with DAPI and observed with a Leica TCS SP8 confocal microscope.

\section{Western Blot Analysis}

Total proteins were extracted from liver tissues with the strong RIPA lysate kit (Beyotime), and the protein concentration was determined by BCA protein method. Proteins were denatured, separated by SDS-PAGE gel, and transferred to polyvinylidene difluoride membranes. The membranes were blocked with 5\% non-fat powdered milk or 3\% BSA in TBST for $2 \mathrm{~h}$ at room temperature and incubated with primary antibodies overnight at $4^{\circ} \mathrm{C}$. The primary antibodies used in this study were against ERK, p-ERK, p38, p-p38, JNK, p-JNK, AKT, p-AKT, NF-кB p65, Bax, Bcl-2 (all from Cell Signaling Technology, Danvers, MA, USA), MXRA7 (Sigma, St. Louis, MO, USA), GAPDH (SUNGENE, Tianjin, China), and $\beta$-actin (ImmunoWay, Plano, TX, USA). Following washes with TBST three times, the membranes were incubated with HRP-conjugated goat anti-rabbit IgG or goat anti-mouse IgG antibody (ImmunoWay) for $1.5 \mathrm{~h}$ at room temperature. After washing off the unbound antibody three times with TBST, the protein bands were detected by an enhanced chemiluminescence kit (Beyotime) using a CLiNX Science Instrument (Shanghai, China). The intensity of the target protein bands was calculated using Image J software.

\section{Statistical Analysis}

All data, when appropriate, are presented as mean \pm SD with sample size (as indicated as $n=$ ) and repeated times of experiments detailed in figure legends. Statistical analysis was performed using the Graphpad prism 5 software (Graphpad, San Diego, CA, USA). One-way of ANOVA analysis and Student's $t$-test (unpaired, twotailed) were used for statistical analysis. $p<0.05$ was considered to be statistically significant $\left(^{\star}\right),<0.01$ or 0.001 was shown as ${ }^{\star *}$ or ${ }^{* * *}$, respectively.

\section{RESULTS}

\section{MXRA7 Deficiency Alleviates While MXRA7 Overexpression Aggravates $\mathrm{CCl}_{4}$-Induced $\mathbf{A L I}$ in Mice}

To evaluate the hypothetical role of MXRA7 in murine ALI model, WT and MXRA7 ${ }^{-1-}$ mice, as well as pMC-MXRA7 mediated MXRA7-overexpressing mice, were compared. The overexpression of MXRA7 in the HGT-pulsed liver was confirmed at both mRNA and protein levels (Figure S2 in Supplementary Material). Compared with controls in WT mice, deficiency of MXRA7 prolonged the survival of mice after $\mathrm{CCl}_{4}$ treatment 
(Figure 1A), while the overexpression of MXRA7 in liver slightly but statistically significantly increased the mortality of mice (Figure 1B). To further confirm the effect of MXRA7 on ALI, the levels of ALT and AST in serum were measured, and histopathological phenotypes in liver were examined. While both transferases were significantly increased in serum in both WT and MXRA7 ${ }^{-1-}$ mice upon $\mathrm{CCl}_{4}$ treatment, the deficiency of MXRA7 markedly impaired the increase of serum ALT and AST (Figure 1C), while the overexpression of MXRA7 increased the amounts of serum ALT and AST (Figure 1D). As a marker enzyme in the process of $\mathrm{CCl}_{4}$-induced liver injury, expression of CYP2E1 in livers of these mice was compared. It was found that MXRA7 deficiency decreased while MXRA7 overexpression increased the expression of CYP2E1, respectively (Figure 1E). When the livers were subjected to histological analysis, the necrotic areas around the central vein and centrilobular regions in $\mathrm{CCl}_{4}$-treated $\mathrm{MXRA}^{-/-}$mice were significantly decreased when compared with that in WT mice (Figure 1F), and MXRA7 overexpression manifested an opposite effect to that of MXRA7 deficiency (Figure 1G). These findings indicated that MXRA7 overexpression promoted ALI development in $\mathrm{CCl}_{4}$-challenged mice, while MXRA7 deficiency protected mice from such injury.
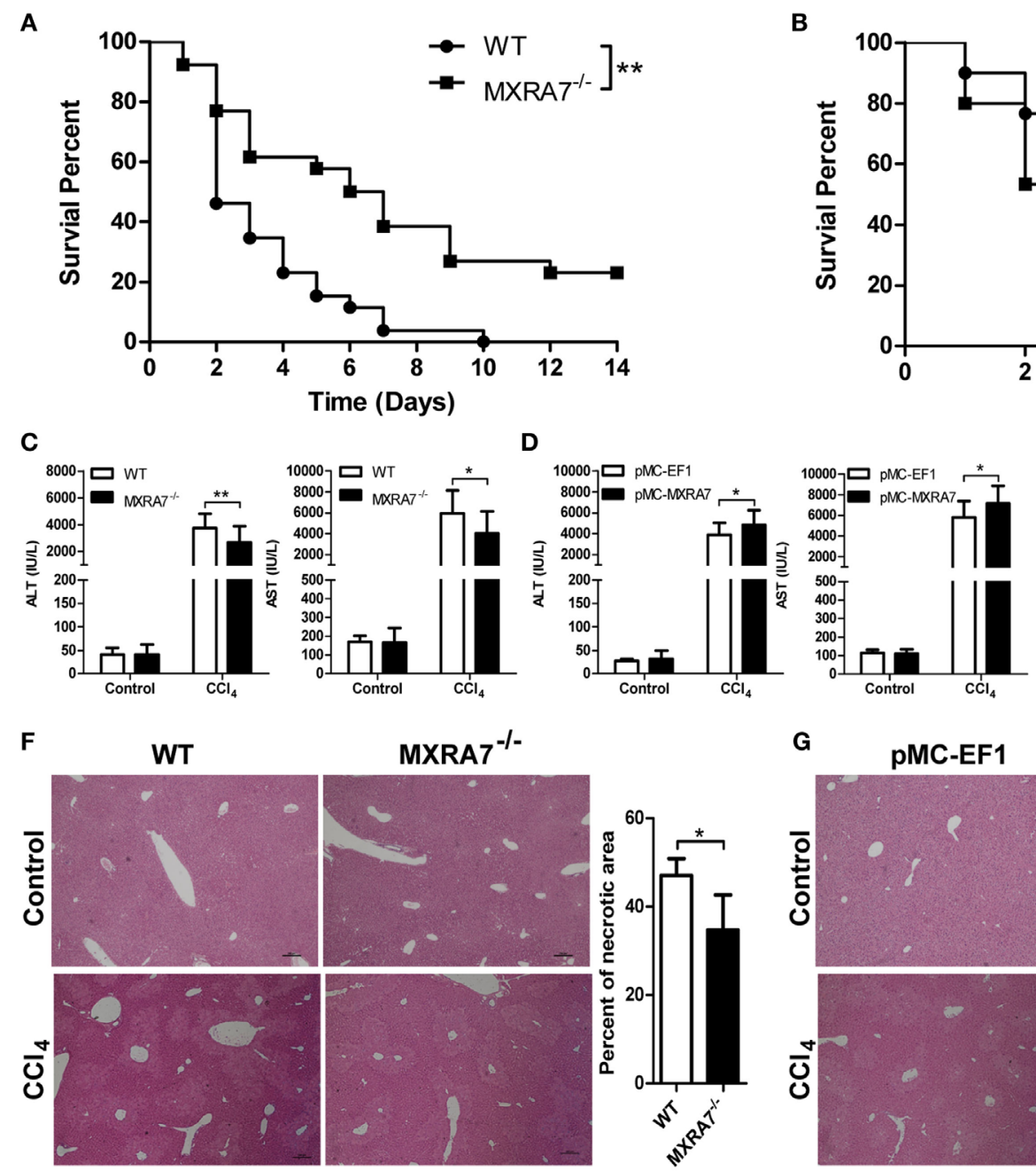

G
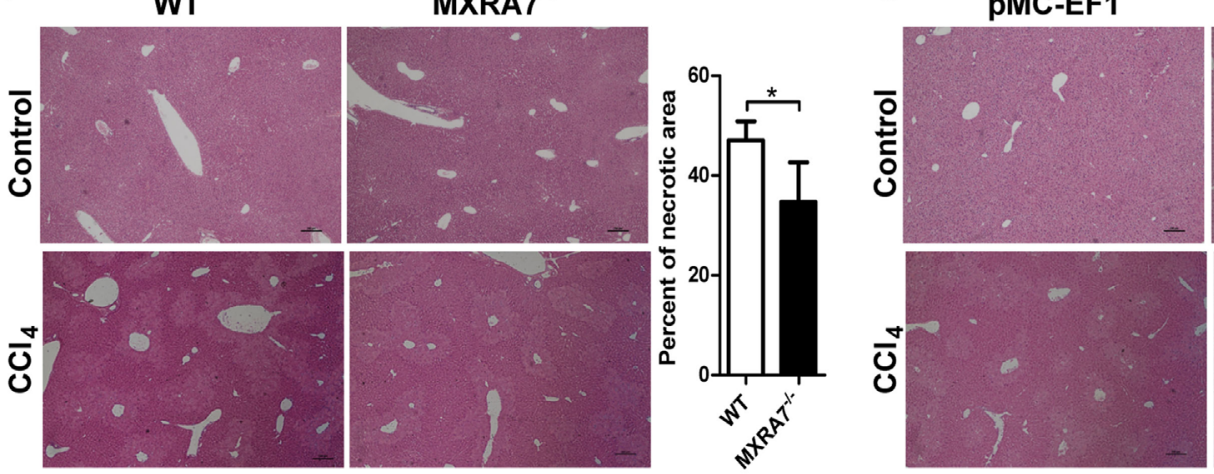

PMC-MXRA7
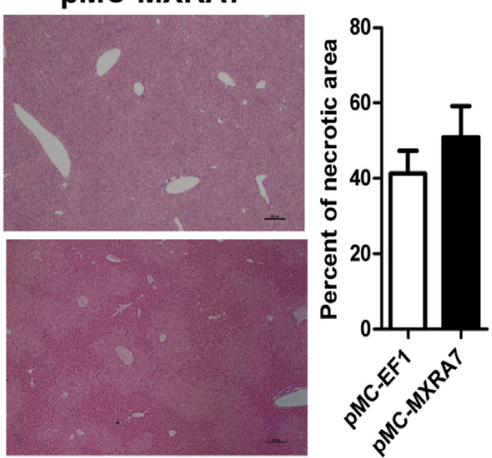

FIGURE 1 | Matrix remodeling associated 7 (MXRA7) deficiency alleviates, while MXRA7 overexpression aggravates CCl4-induced acute liver injury. (A) Wild-type (WT) and MXRA7 ${ }^{-/-}$mice were administered intraperitoneally with $6 \mathrm{ml} / \mathrm{kg} \mathrm{CCl}_{4}(1: 1 \mathrm{corn}$ oil), and survival of animals were monitored daily for 14 days after $n=26$ in each group. The data was expressed as the Kaplan-Meier survival curves and analyzed by the log-rank test. The data shown are the summary of three experiments. (B) C57BL/6 mice were injected with mock pMC-EF1 (control) or pMC-MXRA7 plasmids by hydrodynamic gene transfer method. Three days later, the animals were challenged with $\mathrm{CCl}_{4}$ as above. Survivals were monitored once a day for 7 days after administration. $n=30$ each group. The data shown are the summary of four experiments. (C-G) WT and MXRA7-/- mice, or PMC-EF1 and pMC-MXRA7-pulsed mice, were treated with $1 \mathrm{ml} / \mathrm{kg} C \mathrm{Cl}_{4}$ injection (1:1 corn oil) or control oil. Twenty four hours later, the animals ( $n=6$ for control group, $n=18-23$ ) were sacrificed and serum were harvested measurement of ALT and AST (C,D), while livers $(n=3$ for control group, $n=9$ for $\mathrm{CCl}_{4}$ ) were harvested and subjected to measurement of CYP2E1 mRNAs using reverse transcription-quantitative real-time PCR (E) and structure evaluation after histological hematoxylin and eosin staining $\mathbf{( F , G ) . ~ F o r ~ h i s t o l o g i c a l ~ e v a l u a t i o n , ~ n e c r o t i c ~ a r e a s ~ w e r e ~ d e t e r m i n e d ~ b y ~ m i c r o s c o p y . ~ T h e ~}$ percentage of necrotic area was determined by dividing the sum area of necrosis by the sum of the total liver area of four fields. One representative section is shown for each group (original magnification: 40x). The data shown are the summary of three experiments. ${ }^{*} p<0.05,{ }^{* *} p<0.01$. 


\section{MXRA7 Deficiency Decreases Neutrophils and Macrophages Cells Infiltration in Liver}

The inflammatory cells play important roles in the development of liver injury or related liver diseases, among which neutrophils and macrophages are two classes of well-known players $(13,29,30)$. In order to investigate the effect of MXRA7 on the inflammatory cells during liver injury, we examined the inflammatory cells in spleen and liver by flow cytometry or immunofluorescence staining. The deficiency of MXRA7 significantly decreased the percentage and cell number of Ly6C/Ly6 $6 \mathrm{G}^{+}$ neutrophils and $\mathrm{F} 4 / 80^{+}$macrophages in both spleens and livers (Figures 2A,B). Furthermore, the expressions of CXCL1 and CXCL2, two well-documented neutrophils chemoattractants, were significantly decreased in MXRA7 $7^{-/}$mice (Figure 2C). However, MXRA7 overexpression had no effect on the recruitment of neutrophils and the expression of associated chemokines (Figure S3 in Supplementary Material). These results indicated that deficiency of MXRA7 reduced the expression of CXCL1 and CXCL2, presumably suppressed the recruitment of neutrophils.
MXRA7 Deficiency Decreases the Numbers of $\mathrm{CD}^{+} \mathrm{T}$ Cells and Secretion of IFN $\gamma$ and TNF $\alpha$

$\mathrm{T}$ cells had been suggested as both targets and effector cells in $\mathrm{CCl}_{4}$-induced injury (31). To check if MXRA7 participated in liver injury processes via the immune compartment in above liver injury model, $\mathrm{T}$ cells in liver as well as spleen were analyzed by flow cytometry. Compared with WT group, MXRA7 deficiency reduced the numbers of $\mathrm{CD}^{+} \mathrm{T}$ cells and $\mathrm{CD}^{+} \mathrm{T}$ cells, and the effector cells (CD62 $\left.\mathrm{L}^{-} \mathrm{CD} 44^{+}\right)$in spleens (Figure 3A). MXRA7 deficiency also reduced $\mathrm{CD}^{+} / \mathrm{CD}^{+}$ratio and the number of $\mathrm{CD} 8^{+}$ $\mathrm{T}$ cells, while decreased $\mathrm{CD} 8^{+} \mathrm{T}$ effector cells in livers (Figure 3B). Since T or NK cells-derived cytokines were responsible for induction of inflammation that aggravates liver injury $(32,33)$, we examined IFN $\gamma$ and TNF $\alpha$ secretion by T and NK cells. While the percentages and cell numbers of $\mathrm{CD} 4^{+} \mathrm{T}$ and $\mathrm{CD} 8^{+} \mathrm{T}$ producing IFN $\gamma$ were significantly decreased in spleens of MXRA $7^{-1-}$ mice (Figure 4A), the cell numbers of $\mathrm{CD} 4^{+} \mathrm{T}$ and $\mathrm{CD} 8^{+} \mathrm{T}$ producing IFN $\gamma$ and TNF $\alpha$ were decreased in livers of $\mathrm{MXRA}^{-/-}$mice as

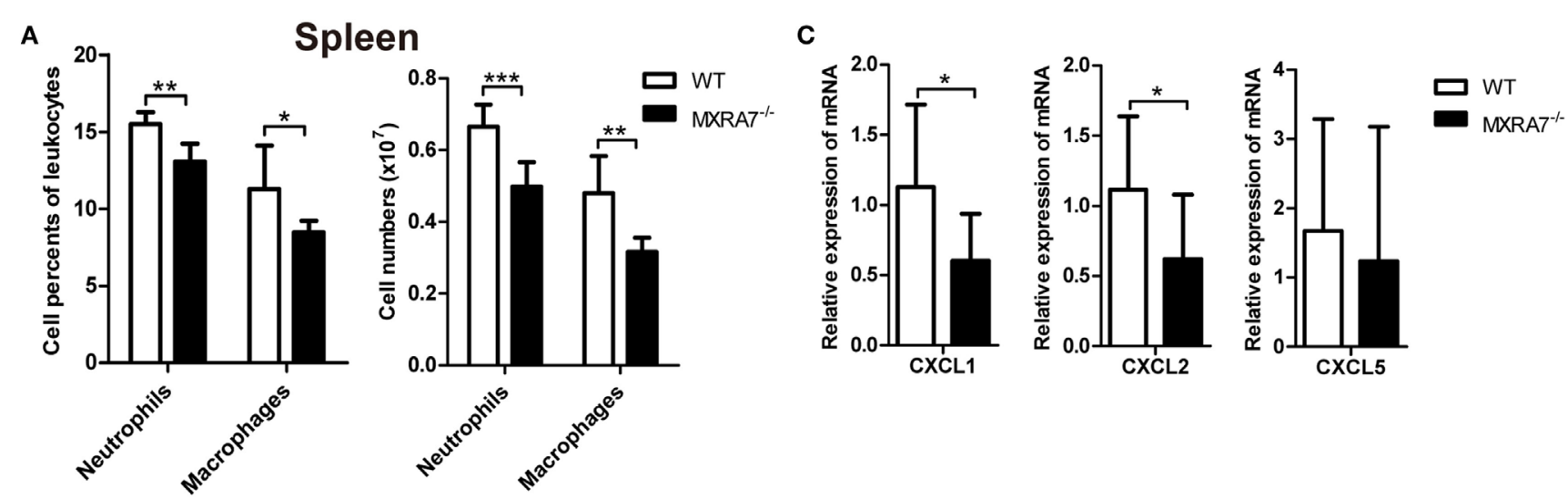

B
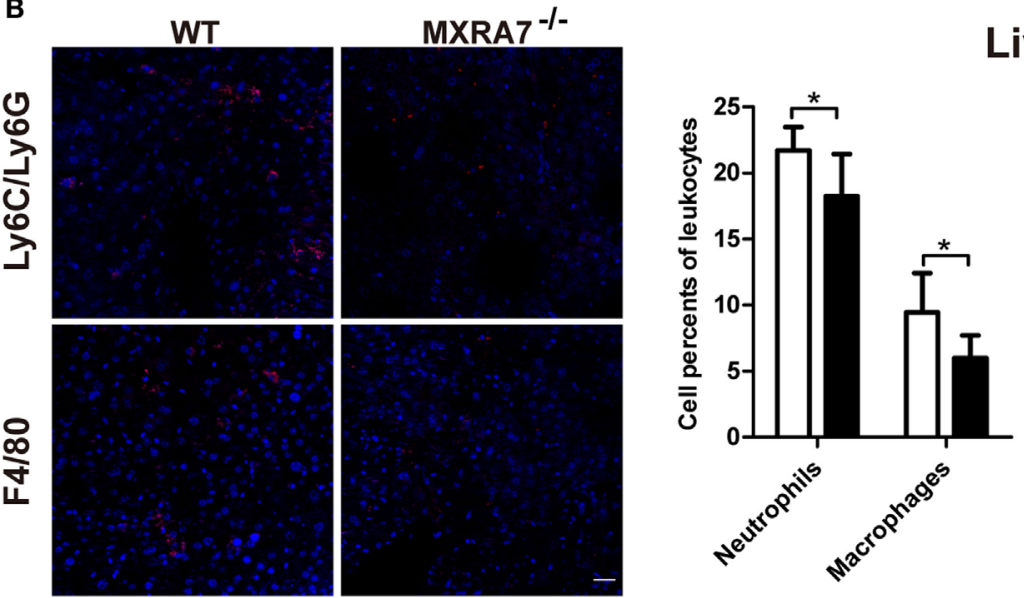

Liver

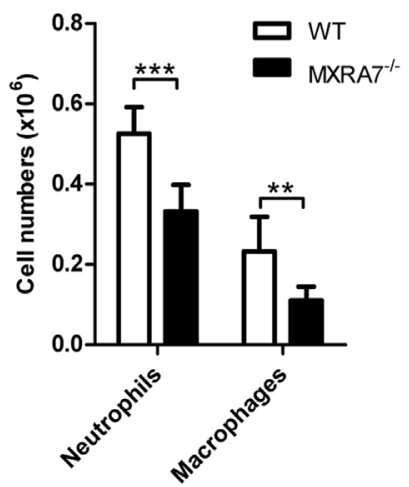

FIGURE 2 | Matrix remodeling associated 7 (MXRA7) deficiency decreases neutrophils and macrophages infiltration in liver. (A,B) Splenocytes and intrahepatic leukocytes were isolated from $1 \mathrm{ml} / \mathrm{kg} \mathrm{CCl}$-challenged wild-type (WT) and MXRA7-/- mice ( $n=7$ each group) $24 \mathrm{~h}$ after CCl 4 injection and used for FACS analysis. (B) Immunofluorescence staining of Ly6C/Ly6G (in red) and F4/80 (in red) in liver sections from CCl 4 -treated WT and MXRA7 ${ }^{-/-}$mice. Scale bar $=25 \mu m$. Ly6C/ Ly6G+ neutrophils and F4/80+ macrophages in spleen (A) and in liver (B) were measured. Data shown are the representative of three independent experiments. (C) Livers were harvested from mice which were sacrificed $24 \mathrm{~h}$ after $1 \mathrm{ml} / \mathrm{kg} \mathrm{CCl}_{4}$ injection. Expression of CXCL1, CXCL2, and CXCL5 mRNAs in livers was detected by reverse transcription-quantitative real-time PCR. The data shown are the summary of three experiments. ${ }^{\star} p<0.05$, ${ }^{\star \star} p<0.01$. 
well (Figure 4B). The numbers of NK cells producing IFN $\gamma$ decreased in both spleens and livers of $\mathrm{MXRA}^{-/-}$mice (Figures 4A,B), while the T cells and production of IFN $\gamma$ and TNF $\alpha$ showed no difference between MXRA7 overexpression and control group
(Figures S4 and S5 in Supplementary Material). These data suggested that MXRA7 deficiency might alleviate liver injury by reducing $\mathrm{CD}^{+} \mathrm{T}$ cells and suppressing the production of IFN $\gamma$ and TNF $\alpha$ from T cells.

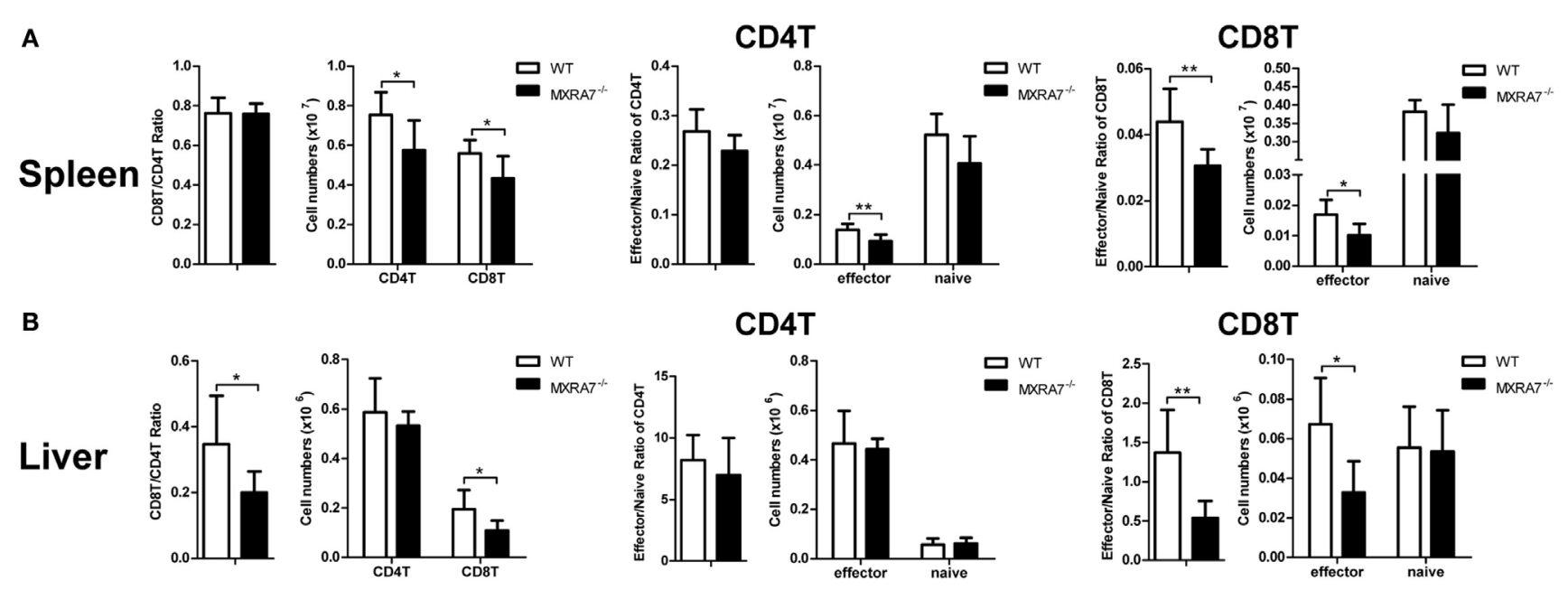

FIGURE 3 | Matrix remodeling associated 7 (MXRA7) deficiency decreases the numbers of CD8 ${ }^{+}$T cells. Mice from wild-type $\left(\right.$WT) and MXRA7 ${ }^{-/-}$groups $(n=7$ each group) were sacrificed $24 \mathrm{~h}$ after $1 \mathrm{ml} / \mathrm{kg} \mathrm{CCl} 4$ injection. Splenocytes and intrahepatic leukocytes were isolated for FACS analysis. (A) Flow cytometric analysis showing slight but statistically significant decrease of CD8 ${ }^{+} \mathrm{T}$ cells and effector cells (CD62 L-CD44+) in CD4+ ${ }^{+}$, CD8 ${ }^{+} \mathrm{T}$ cells in spleen. (B) Flow cytometric analysis of $\mathrm{CD}^{+} \mathrm{T}$ and $\mathrm{CD} 8^{+} \mathrm{T}$ cells, and effector cells $\left(\mathrm{CD} 62 \mathrm{~L}^{-} \mathrm{CD} 44^{+}\right)$in liver. Data shown are the representative of three independent experiments. ${ }^{*} p<0.05$, ${ }^{\star *} p<0.01$.

A

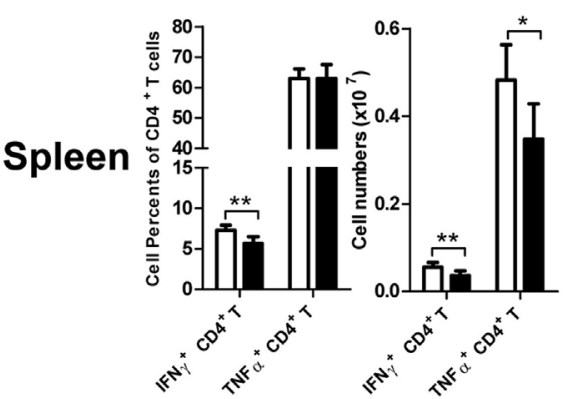

B

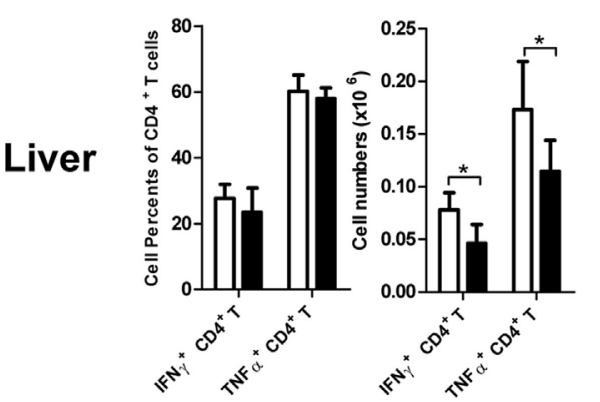

CD8T

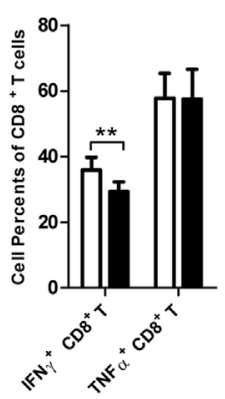

CD8T
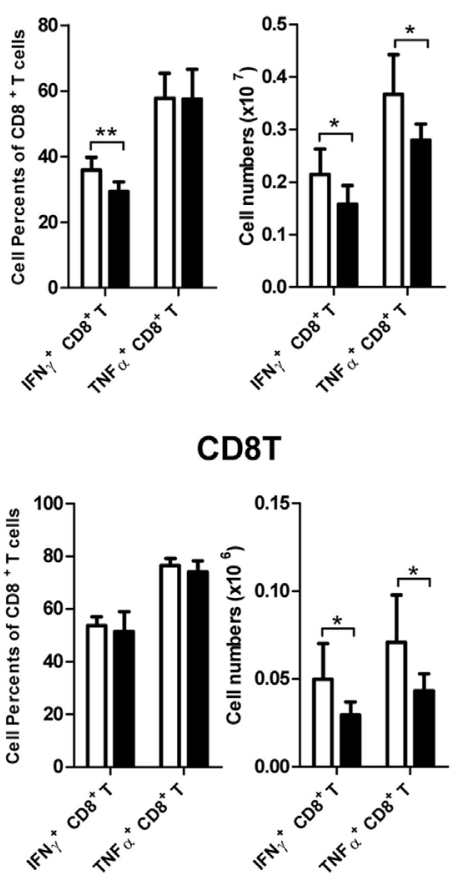

NK
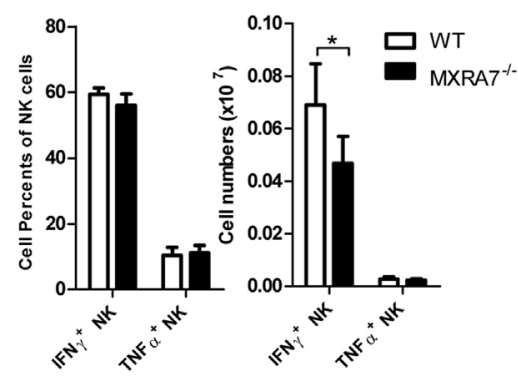

NK

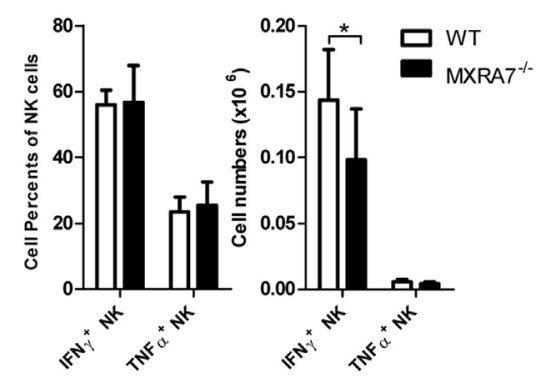

FIGURE 4 | Matrix remodeling associated 7 (MXRA7) deficiency inhibits IFN $\gamma$ and TNF $\alpha$ production in T cells. Twenty four hours after 1 ml/kg CCl ${ }_{4}$ injection, mice from different groups ( $n=7$ each group) were sacrificed. Splenocytes (A) and intrahepatic leukocytes (B) were isolated, stimulated, and stained for intracellular cytokines in combination with cell surface staining. The percentages of IFN $\gamma^{+}$in $\mathrm{CD} 4^{+} \mathrm{T}$ and $\mathrm{CD} 8^{+} \mathrm{T}$ cells were decreased in MXRA7 ${ }^{-/-}$spleens. The numbers of IFN $\gamma^{+}$and TNF $\alpha^{+}$in $\mathrm{CD}^{+} \mathrm{T}$ and $\mathrm{CD} 8^{+} \mathrm{T}$ cells were decreased in both spleens and livers of MXRA7 ${ }^{-/}$mice. Data shown are the representative of three independent experiments. ${ }^{*} p<0.05,{ }^{* *} p<0.01$. 
MXRA7 Deficiency Reduces the Expression of Pro-Inflammatory Cytokines in ALI Model

The inflammatory cytokines of serum IFN $\gamma$, IL-6, TNF, MCP-1, IL-12p70, and IL-10 were determined by CBA mouse inflammation kit. The deficiency of MXRA7 decreased the level of serum IFN $\gamma$ (Figure 5A), and the overexpression of MXRA7 increased IFN $\gamma$ level (Figure 5B). Moreover, we also measured the expression of pro-inflammatory cytokines in livers. The mRNA expressions of IFN $\gamma$ and IL- 6 were significantly decreased in MXRA7 ${ }^{-/-}$group when compared to WT group (Figure 5C), while MXRA7 overexpression elevated the mRNA expression of IFN $\gamma$ (Figure 5D). None of other tested cytokines or their genes manifested significant change. These results suggested that IFN $\gamma$ was the main pro-inflammatory cytokines mediating the differential responses to $\mathrm{CCl}_{4}$-induced injury in mice under different MXRA7 context.

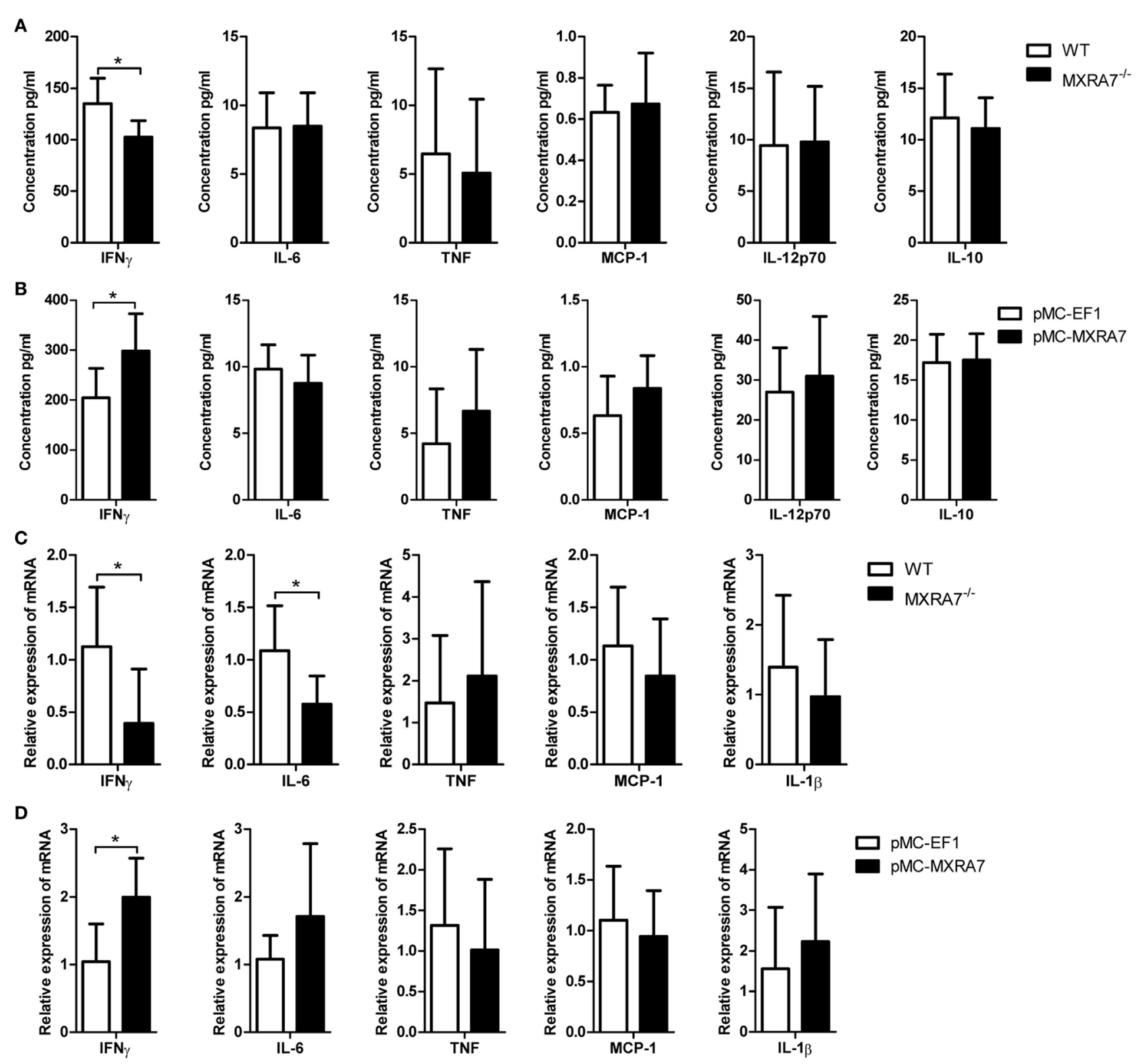

FIGURE 5 | Matrix remodeling associated 7 (MXRA7) deficiency inhibits and MXRA7 overexpression promotes the expression of pro-inflammatory cytokines. (A,B) Serum was collected from different groups of mice $24 \mathrm{~h}$ after $1 \mathrm{ml} / \mathrm{kg} \mathrm{CCl}_{4}$ injection. Serum IFN $\gamma, \mathrm{IL}-6, \mathrm{TNF}, \mathrm{MCP}-1, \mathrm{IL}-12 \mathrm{p} 70$, and IL-10 were determined using cytometric bead array mouse inflammation kit. (C,D) Livers were isolated from different groups of mice $24 \mathrm{~h}$ after $1 \mathrm{ml} / \mathrm{kg} \mathrm{CCl} 4$ injection. Expression of IFN $\gamma$, IL-6, TNF, MCP-1, and IL-1 $\beta$ mRNAs in livers was detected by reverse transcription-quantitative real-time PCR. Data are presented as the summary of three experiments. ${ }^{*} p<0.05$. 


\section{MXRA7 Deficiency Inhibits While MXRA7 Overexpression Promotes the Expression of Fibronectin and TIMP1}

Liver injury induces inflammation and expression of extracellular matrix proteins, such as fibronectin and collagen I (COL1A1) (34, 35). Immunofluorescence staining showed that MXRA7 deficiency decreased the expression of fibronectin in liver compared to WT mice (Figure 6A), while MXRA7 overexpression increased fibronectin expression (Figure 6B). However, MXRA7 had no effect on the expression of COL1A1 (Figures 6C,D). Tissue inhibitor of metalloproteinase 1 was also tested since it is a well-documented modulator of matrix remodeling (36). MXRA7 $^{-1-}$ mice showed lower expression of TIMP1 mRNA than WT mice, and MXRA7 overexpression increased the mRNA level of TIMP1 (Figures 6C,D). These data suggest that MXRA7 plays a role in the reconstruction of extracellular matrix.

\section{MXRA7 Deficiency Suppresses the Cell Apoptosis Pathway and Inflammatory Pathway}

To clarify whether MXRA7 could affect the apoptosis of hepatocytes, the TUNEL assay was performed. MXRA7 deficiency inhibited cell apoptosis and MXRA7 overexpression promoted cell apoptosis upon $\mathrm{CCl}_{4}$ treatment (Figures 7A,B). The expressions of Bcl-2 and Bax in livers were also compared among different groups. After $\mathrm{CCl}_{4}$ treatment, the protein expressions of the proapoptotic protein Bax were decreased in livers from
MXRA7 $7^{-/}$mice, while the levels of the antiapoptotic factor Bcl-2 was significantly increased (Figure 7C). On the contrary, MXRA7 overexpression increased the expression of Bax as compared to control group (Figure 7D).

To understand the underlying molecular mechanisms of the effects of MXRA7 on $\mathrm{CCl}_{4}$-induced liver injury, we examined the MAPK and AKT/NF- $\mathrm{KB}$ signaling pathways, which are known to regulate cell apoptosis and inflammation. Western blot analysis showed that MXRA7 deficiency reduced the phosphorylated protein levels of ERK and $\mathrm{p} 38$ when compared to WT mice (Figure 7E), while MXRA7 overexpression increased the levels of p-ERK and p-p38 after $\mathrm{CCl}_{4}$ treatment (Figure 7F). However, MXRA7 deficiency or overexpression did not show significant effect on phosphorylation of JNK (Figure S6 in Supplementary Material). MXRA7 deficiency also decreased the expression of p-AKT and NF- $\mathrm{kB}$ p 65 (Figure 7G), while MXRA7 overexpression increased the expression of p-AKT after $\mathrm{CCl}_{4}$ treatment (Figure $\left.7 \mathrm{H}\right)$. Thus, the protective roles of MXRA7 deficiency against $\mathrm{CCl}_{4}$-induced hepatocyte apoptosis and inflammation might be associated with suppressing MAPK and AKT/NF-kB pathways.

\section{DISCUSSION}

Since named in 2002 (22), MXRA7 had been just mentioned in some studies without any purpose investigation into its biological functions. Previous studies noted that MXRA7 was overexpressed in childhood acute lymphoblastic leukemia and in ovarian endometriomas $(37,38)$. In an effort to characterize the functions of

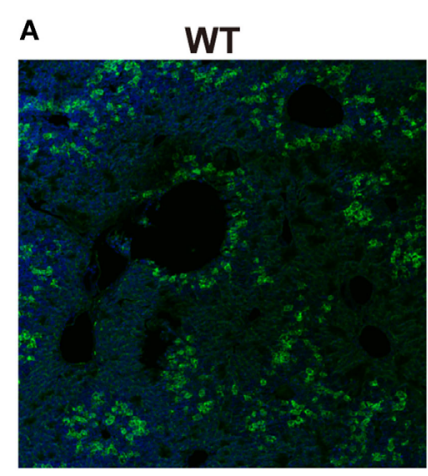

C

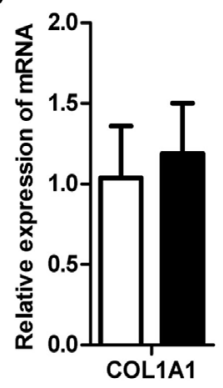

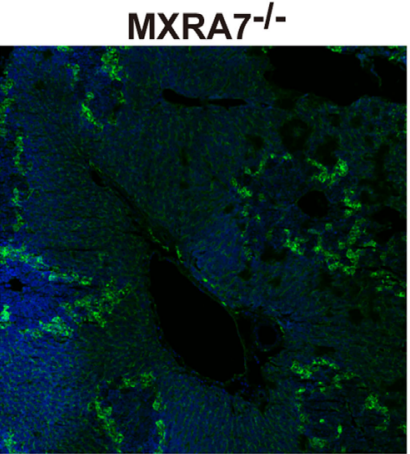

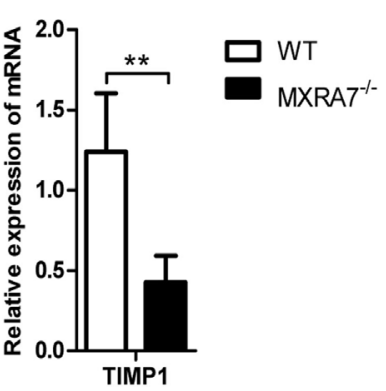

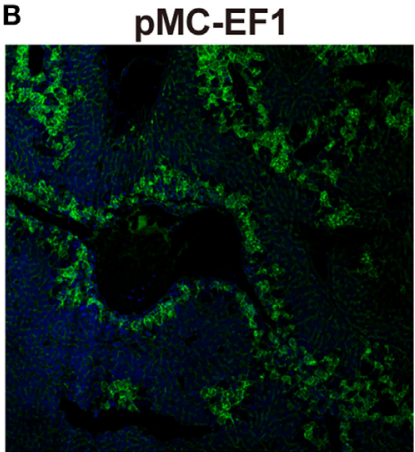

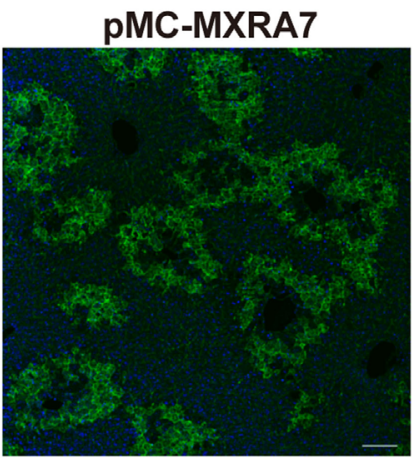

D
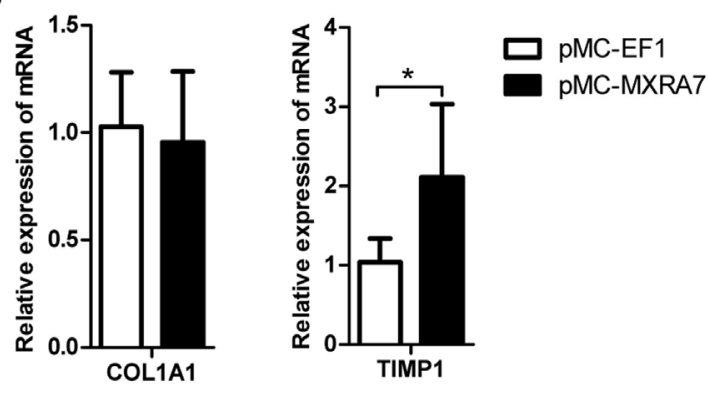

FIGURE 6 | Matrix remodeling associated 7(MXRA7) deficiency inhibits and MXRA7 overexpression promotes the expression of fibronectin and TIMP1. Livers were isolated from different groups of mice $24 \mathrm{~h}$ after $1 \mathrm{ml} / \mathrm{kg} \mathrm{CCl} 4$ injection. (A,B) Expression of fibronectin (in green) in livers was detected using immunofluorescence analysis. Representative images from different groups are shown. Scale bar $=100 \mu \mathrm{m}$. (C,D) Expression of COL1A1 and TIMP1 mRNAs in livers was detected by reverse transcription-quantitative real-time PCR. Data are presented as the summary of two experiments. ${ }^{\star} p<0.05,{ }^{\star \star} p<0.01$. 
MXRA7, our lab had found that MXRA7 was involved in the pathological process of ocular inflammatory models (21) and MXRA7 might play a role in tissue injury, wound healing, and cancer (manuscripts under review).

In the current study, the potential role of MXRA7 in liver disease was investigated in mice by utilizing the $\mathrm{CCl}_{4}$-induced liver injury model. This model has been widely used to study both acute injury and following chronic fibrosis (39-41). We found that MXRA7 overexpression aggravated liver injury, and MXRA7 deficiency protected the liver against $\mathrm{CCl}_{4}$-induced liver injury (Figure 1). Serum AST and ALT levels, which were often used as indicators of hepatic damage and functional integrity of liver (42), manifested changes in line with the animal survival or histological changes. $\mathrm{CCl}_{4}$ could induce liver damage through CYP2E1 (43), though the necrotic area would possibly not produce CYP2E1 anymore, MXRA7 might affect liver injury partly by regulating the level of CYP2E1. In summary, all these results indicated a hepatoprotective effect of MXRA7 deficiency on $\mathrm{CCl}_{4}$-induced ALI. In another word, MXRA7 might be a positive modulator of $\mathrm{CCl}_{4}$-induced ALI.
Though the main functions of the liver are focused on metabolism, it is also an immunologic organ since the immune cells resided in the liver are involved in the development of inflammation and fibrosis when responding to various insults (44). In $\mathrm{CCl}_{4}$-induced liver inflammation and injury model, lymphocytes, neutrophils, and macrophages in liver tissues play important roles through secreting cytokines and chemokines (13, 45-47). Previous study reported that $\mathrm{CD}^{+} \mathrm{T}$ cells could induce more liver injury and fibrosis in mice treated with $\mathrm{CCl}_{4}$, and $\mathrm{CD}^{+} /$ $\mathrm{CD}^{+}$ratio reduction also involved in induction of liver fibrosis in human $(40,48)$. The data presented here demonstrated that MXRA7 deficiency not only impaired infiltration of neutrophils and marcrophages in liver induced by $\mathrm{CCl}_{4}$ (Figure 2) but also decreased the number of $\mathrm{CD} 8^{+} \mathrm{T}$ cells and $\mathrm{CD} 8^{+} / \mathrm{CD} 4^{+}$ratio in liver of MXRA7 ${ }^{-1-}$ mice compared to WT mice (Figure 3). In line with this observation, MXRA7 deficiency suppressed the production of IFN $\gamma$ and TNF $\alpha$ in T cells (Figure 4) and suppressed the expression (at mRNA level) of IFN $\gamma$ and IL-6 in liver, hence decreased the protein level of IFN $\gamma$ in serum. Meanwhile, MXRA7 overexpression increased the IFN $\gamma$ mRNA in liver and
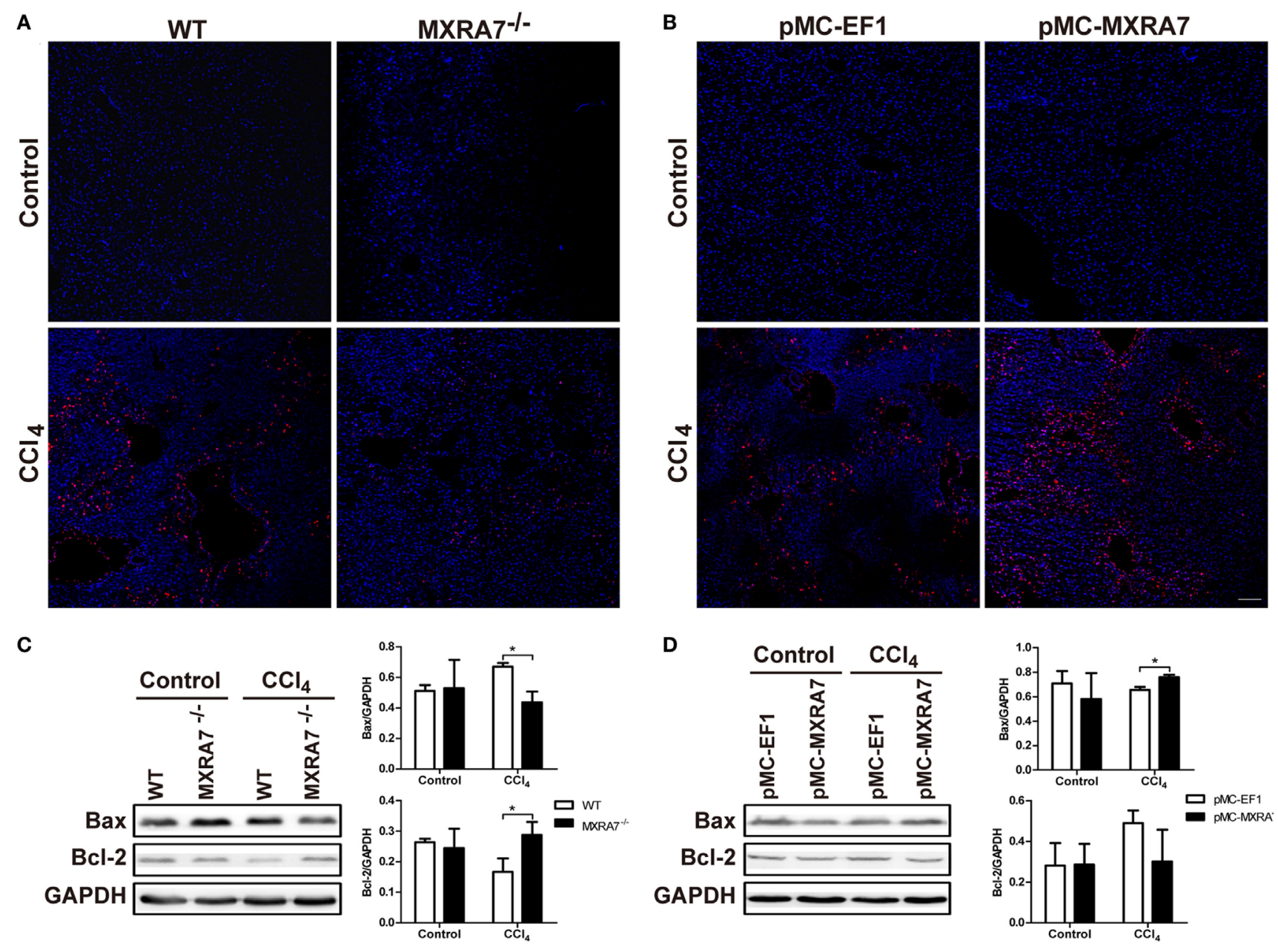

FIGURE 7 | Continued 
E

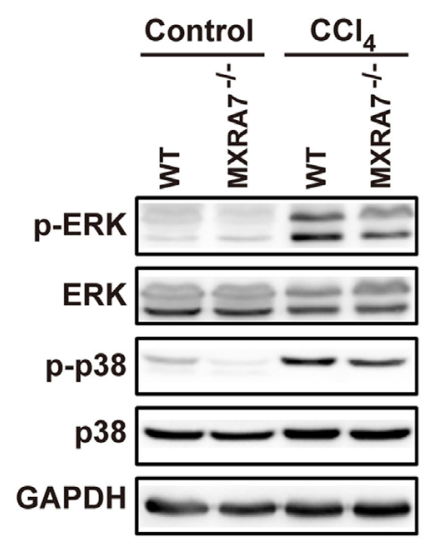

G

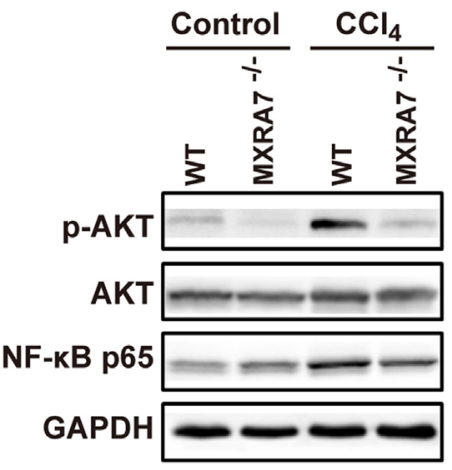

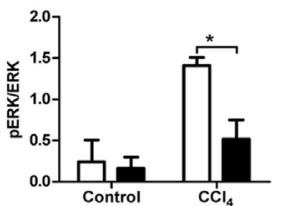

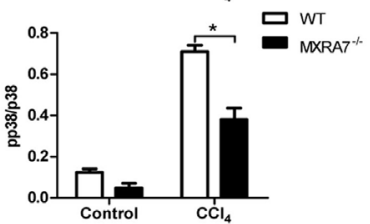

$\mathbf{F}$
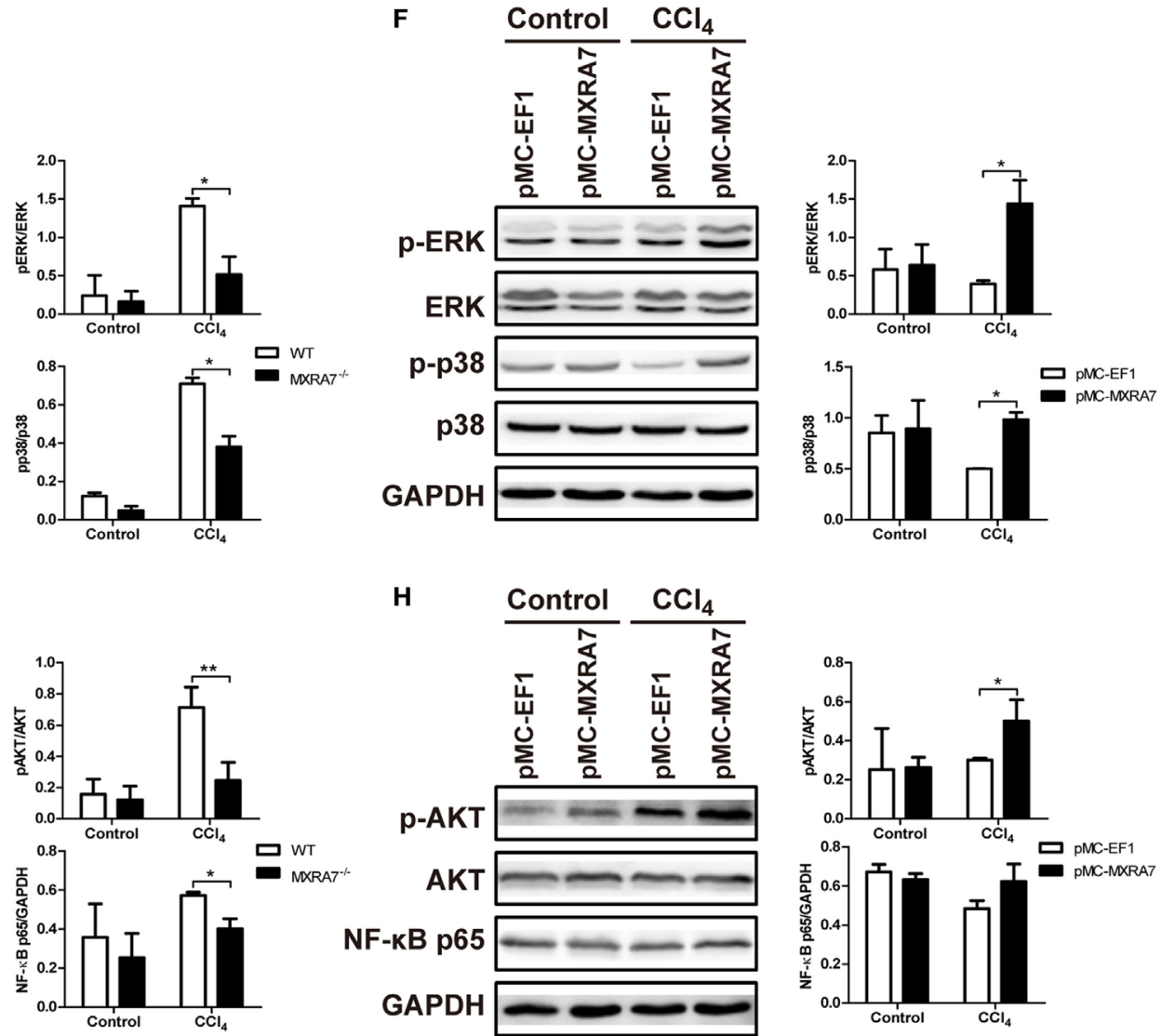

H

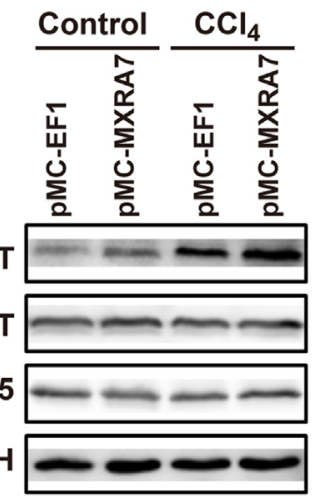

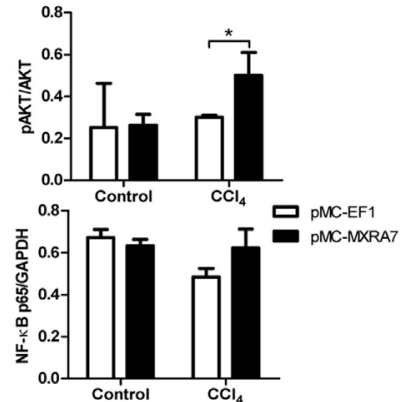

FIGURE 7 | Matrix remodeling associated 7 (MXRA7) deficiency suppresses the cell apoptosis pathway and inflammatory pathway in livers. Livers were harvested from different groups of mice $24 \mathrm{~h}$ after $1 \mathrm{ml} / \mathrm{kg} \mathrm{CCl}_{4}$ injection. (A,B) Hepatocyte apoptosis in liver was analyzed using TUNEL staining (in red). Representative images from different groups are shown. Scale bar $=100 \mu \mathrm{m}$. And proteins were extracted from livers for western blot analysis of Bax and Bcl-2 (C,D) $p$-ERK, ERK, p-p38, p38 (E,F), p-AKT, AKT, and NF-kB p65 (G,H). Representative images shown are the representative of three independent experiments. ${ }^{*} p<0.05,{ }^{\star *} p<0.01$.

protein in serum. Collectively, these data showed that when MXRA7 was deficient in animals, $\mathrm{CCl}_{4}$-induced inflammatory or immune cells activation were decreased, leading to an alleviated liver injury than in WT host receiving same challenge.

Lastly, cell apoptosis and inflammatory signaling pathways associated with $\mathrm{CCl}_{4}$-induced injury (49) were measured. MXRA7 deficiency suppressed cell apoptosis, decreased Bax expression, and increased Bcl-2 expression, while MXRA7 overexpression promoted cell apoptosis and upregulated the expression of Bax (Figure 7). When the hepatic apoptosis pathways, e.g., MAPK signaling pathway, were compared in context of ALI models, the phosphorylation levels of ERK and p38 regulating cell apoptosis were downregulated in $\mathrm{MXRA}^{-/-}$mice and upregulated in MXRA7 overexpression mice. AKT/NF- $\kappa$ B pathway has dual function in pro-inflammatory and cell survival, the unbalance of $\mathrm{NF}-\kappa \mathrm{B}$ activation may cause increased inflammation or insufficient protection from cell apoptosis $(50,51)$. However, the effect of MXRA7 deficiency or overexpression on the AKT phosphorylation or p65 expression was a little bit complicated in $\mathrm{CCl}_{4^{-}}$ induced ALI. The overall impression was that MXRA7 deficiency depressed AKT phosphorylation and NF- $\mathrm{B}$ p65 expression while
MXRA7 overexpression increased AKT phosphorylation (Figure 7). These results suggested that in the studied ALI model, MXRA7 not only mediated liver injury via the inflammation or immune compartment but also via acting in/on hepatocytes directly or indirectly.

In summary, this study represented the first effort to explore the possibility that the seldom-addressed gene MXRA7 was involved in ALI. Using genetically MXRA7-deficient mice and assisted with HGT-mediated liver-specific overexpression of MXRA7, we were able to confirm that MXRA7 played a positive role in initiation of $\mathrm{CCl}_{4}$-induced ALI. It will be of interest to investigate whether such a hypothesis for MXRA7 function was applicable with other acute liver injuries, or even with chronic liver injuries. For example, repeated injection of $\mathrm{CCl}_{4}$ in mice leads to chronic liver fibrosis, a process that is more closely related with matrix remodeling. This said, though the results that MXRA7 deficiency decreased and MXRA7 overexpression increased the expression of fibronectin and TIMP1 in murine livers (Figure 6) were still preliminary, they strongly implied that MXRA7 might also be involved in such chronic liver injuries as those induced by repeated $\mathrm{CCl}_{4}$ challenge, heavy alcohol consumption, drug 
intoxication, or consistent virus infections. Should all these hypotheses be confirmed by future studies, MXRA7 might serve a promising new therapeutic target for preventing or treating those liver injuries. However, in spite of the current data demonstrating the potential significance of MXRA7 in liver injury, much more investigations are guaranteed to help fully understand the role of MXRA7 in ALI, ALI-based diseases, or in overall physiology or pathology of the liver.

\section{ETHICS STATEMENT}

All animal experiments were carried out in accordance with the Guidelines on the Humane Treatment of Laboratory Animals (Ministry of Science and Technology of China, 2006) and approved by Ethical Committee of The First Affiliated Hospital of Soochow University. All measures were taken to ensure the humane treatment of research animals.

\section{REFERENCES}

1. Sun B, Karin M. NF-kappaB signaling, liver disease and hepatoprotective agents. Oncogene (2008) 27(48):6228-44. doi:10.1038/onc.2008.300

2. Kershenobich Stalnikowitz D, Weissbrod AB. Liver fibrosis and inflammation. A review. Ann Hepatol (2003) 2(4):159-63.

3. Wang FS, Fan JG, Zhang Z, Gao B, Wang HY. The global burden of liver disease: the major impact of China. Hepatology (2014) 60(6):2099-108. doi:10.1002/ hep. 27406

4. Williams R. Global challenges in liver disease. Hepatology (2006) 44(3):521-6. doi:10.1002/hep.21347

5. Ingawale DK, Mandlik SK, Naik SR. Models of hepatotoxicity and the underlying cellular, biochemical and immunological mechanism(s): a critical discussion. Environ Toxicol Pharmacol (2014) 37(1):118-33. doi:10.1016/ j.etap.2013.08.015

6. Muhl H. STAT3, a key parameter of cytokine-driven tissue protection during sterile inflammation - the case of experimental acetaminophen (Paracetamol)-induced liver damage. Front Immunol (2016) 7:163. doi:10.3389/ fimmu.2016.00163

7. Jaeschke H, McGill MR, Ramachandran A. Oxidant stress, mitochondria, and cell death mechanisms in drug-induced liver injury: lessons learned from acetaminophen hepatotoxicity. Drug Metab Rev (2012) 44(1):88-106. doi:10.3109/03602532.2011.602688

8. Zhang DG, Zhang C, Wang JX, Wang BW, Wang H, Zhang ZH, et al. Obeticholic acid protects against carbon tetrachloride-induced acute liver injury and inflammation. Toxicol Appl Pharmacol (2017) 314:39-47. doi:10.1016/j.taap.2016.11.006

9. Malhi H, Gores GJ. Cellular and molecular mechanisms of liver injury. Gastroenterology (2008) 134(6):1641-54. doi:10.1053/j.gastro.2008.03.002

10. Fujii T, Fuchs BC, Yamada S, Lauwers GY, Kulu Y, Goodwin JM, et al. Mouse model of carbon tetrachloride induced liver fibrosis: histopathological changes and expression of CD133 and epidermal growth factor. BMC Gastroenterol (2010) 10:79. doi:10.1186/1471-230X-10-79

11. Martinez M, Mourelle M, Muriel P. Protective effect of colchicine on acute liver damage induced by CCl4. Role of cytochrome P-450. J Appl Toxicol (1995) 15(1):49-52.

12. Niu X, Liu F, Li W, Zhi W, Yao Q, Zhao J, et al. Hepatoprotective effect of fraxin against carbon tetrachloride-induced hepatotoxicity in vitro and in vivo through regulating hepatic antioxidant, inflammation response and the MAPK-NF-kappaB signaling pathway. Biomed Pharmacother (2017) 95: 1091-102. doi:10.1016/j.biopha.2017.09.029

13. Tacke F, Luedde T, Trautwein C. Inflammatory pathways in liver homeostasis and liver injury. Clin Rev Allergy Immunol (2009) 36(1):4-12. doi:10.1007/s12016-008-8091-0

14. Seo W, Eun HS, Kim SY, Yi HS, Lee YS, Park SH, et al. Exosome-mediated activation of toll-like receptor 3 in stellate cells stimulates interleukin-17

\section{AUTHOR CONTRIBUTIONS}

YW and DL designed the study and wrote the manuscript. DL, ZS, ZJ, LL, YL, BH, BW, and YS performed the experiments. DL, $\mathrm{ZS}$, and ZJ analyzed the data.

\section{FUNDING}

This work was supported by the grants from National Natural Science Foundation of China (81600076 and 81271050) and the China Postdoctoral Science Foundation Grant (2016M600438).

\section{SUPPLEMENTARY MATERIAL}

The Supplementary Material for this article can be found online at https://www.frontiersin.org/articles/10.3389/fimmu.2018.00773/ full\#supplementary-material.

production by gammadelta $\mathrm{T}$ cells in liver fibrosis. Hepatology (2016) 64(2):616-31. doi:10.1002/hep.28644

15. Shim JY, Kim MH, Kim HD, Ahn JY, Yun YS, Song JY. Protective action of the immunomodulator ginsan against carbon tetrachloride-induced liver injury via control of oxidative stress and the inflammatory response. Toxicol Appl Pharmacol (2010) 242(3):318-25. doi:10.1016/j.taap.2009.11.005

16. Wasmuth HE, Tacke F, Trautwein C. Chemokines in liver inflammation and fibrosis. Semin Liver Dis (2010) 30(3):215-25. doi:10.1055/s-0030-1255351

17. Lin X, Huang R, Zhang S, Zheng L, Wei L, He M, et al. Methyl helicterate protects against $\mathrm{CCl} 4$-induced liver injury in rats by inhibiting oxidative stress, NF-kappaB activation, Fas/FasL pathway and cytochrome P4502E1 level. Food Chem Toxicol (2012) 50(10):3413-20. doi:10.1016/j.fct.2012. 07.053

18. Tipoe GL, Leung TM, Liong EC, Lau TY, Fung ML, Nanji AA. Epigallocatechin-3-gallate (EGCG) reduces liver inflammation, oxidative stress and fibrosis in carbon tetrachloride $(\mathrm{CCl} 4)$-induced liver injury in mice. Toxicology (2010) 273(1-3):45-52. doi:10.1016/j.tox.2010.04.014

19. Massey VL, Dolin CE, Poole LG, Hudson SV, Siow DL, Brock GN, et al. The hepatic "matrisome" responds dynamically to injury: characterization of transitional changes to the extracellular matrix in mice. Hepatology (2017) 65(3):969-82. doi:10.1002/hep.28918

20. Poole LG, Arteel GE. Transitional remodeling of the hepatic extracellular matrix in alcohol-induced liver injury. Biomed Res Int (2016) 2016:3162670. doi: $10.1155 / 2016 / 3162670$

21. Jia C, Zhang F, Zhu Y, Qi X, Wang Y. Public data mining plus domestic experimental study defined involvement of the old-yet-uncharacterized gene matrix-remodeling associated 7 (MXRA7) in physiopathology of the eye. Gene (2017) 632:43-9. doi:10.1016/j.gene.2017.08.018

22. Walker MG, Volkmuth W. Cell adhesion and matrix remodeling genes identified by co-expression analysis gene function \& disease volume 3, Issue 3-4. Gene Funct Dis (2002) 3(3-4):109-12. doi:10.1002/gnfd.200290000

23. Pignatelli J, LaLonde SE, LaLonde DP, Clarke D, Turner CE. Actopaxin (alpha-parvin) phosphorylation is required for matrix degradation and cancer cell invasion. J Biol Chem (2012) 287(44):37309-20. doi:10.1074/jbc. M112.385229

24. Kakinuma N, Zhu Y, Wang Y, Roy BC, Kiyama R. Kank proteins: structure, functions and diseases. Cell Mol Life Sci (2009) 66(16):2651-9. doi:10.1007/ s00018-009-0038-y

25. Poveda J, Sanz AB, Fernandez-Fernandez B, Carrasco S, Ruiz-Ortega M, Cannata-Ortiz P, et al. MXRA5 is a TGF-betal-regulated human protein with anti-inflammatory and anti-fibrotic properties. J Cell Mol Med (2017) 21(1):154-64. doi:10.1111/jcmm.12953

26. Bernau K, Torr EE, Evans MD, Aoki JK, Ngam CR, Sandbo N. Tensin 1 is essential for myofibroblast differentiation and extracellular matrix formation. Am J Resp Cell Mol (2017) 56(4):465-76. doi:10.1165/rcmb.20160104OC 
27. Lin D, Lei L, Zhang Y, Hu B, Bao G, Liu Y, et al. Secreted IL-1alpha promotes T-cell activation and expansion of $\mathrm{CD} 11 \mathrm{~b}(+) \mathrm{Gr} 1(+)$ cells in carbon tetrachloride-induced liver injury in mice. Eur J Immunol (2015) 45(7):2084-98. doi:10.1002/eji.201445195

28. Hu B, Bao G, Zhang Y, Lin D, Wu Y, Wu D, et al. Donor NK Cells and IL-15 promoted engraftment in nonmyeloablative allogeneic bone marrow transplantation. J Immunol (2012) 189(4):1661-70. doi:10.4049/jimmunol. 1103199

29. Jaeschke H, Hasegawa T. Role of neutrophils in acute inflammatory liver injury. Liver Int (2006) 26(8):912-9. doi:10.1111/j.1478-3231.2006.01327.x

30. Louis H, Van Laethem JL, Wu W, Quertinmont E, Degraef C, Van den Berg K, et al. Interleukin-10 controls neutrophilic infiltration, hepatocyte proliferation, and liver fibrosis induced by carbon tetrachloride in mice. Hepatology (1998) 28(6):1607-15. doi:10.1002/hep.510280621

31. Delaney B, Strom SC, Collins S, Kaminski NE. Carbon tetrachloride suppresses T-cell-dependent immune responses by induction of transforming growth factor-beta 1. Toxicol Appl Pharmacol (1994) 126(1):98-107. doi:10.1006/ taap.1994.1095

32. Chen M, Huang W, Wang C, Nie H, Li G, Sun T, et al. High-mobility group box 1 exacerbates $\mathrm{CCl}(4)$-induced acute liver injury in mice. Clin Immunol (2014) 153(1):56-63. doi:10.1016/j.clim.2014.03.021

33. Muntane J, Montero JL, Lozano JM, Miranda-Vizuete A, de la Mata M, Mino G. TNF-alpha but not IL-1 alpha is correlated with PGE(1)-dependent protection against acute D-galactosamine-induced liver injury. Can J Gastroenterol (2000) 14(3):175-80. doi:10.1155/2000/416705

34. Duarte S, Baber J, Fujii T, Coito AJ. Matrix metalloproteinases in liver injury, repair and fibrosis. Matrix Biol (2015) 4(4-46):147-56. doi:10.1016/ j.matbio.2015.01.004

35. Jarnagin WR, Rockey DC, Koteliansky VE, Wang SS, Bissell DM. Expression of variant fibronectins in wound healing: cellular source and biological activity of the EIIIA segment in rat hepatic fibrogenesis. J Cell Biol (1994) 127 (6 Pt 2):2037-48. doi:10.1083/jcb.127.6.2037

36. Gieling RG, Burt AD, Mann DA. Fibrosis and cirrhosis reversibility molecular mechanisms. Clin Liver Dis (2008) 12(4):915-37, xi. doi:10.1016/ j.cld.2008.07.001

37. Flotho C, Coustan-Smith E, Pei D, Iwamoto S, Song G, Cheng C, et al. Genes contributing to minimal residual disease in childhood acute lymphoblastic leukemia: prognostic significance of CASP8AP2. Blood (2006) 108(3):1050-7. doi:10.1182/blood-2006-01-0322

38. Veiga-Castelli LC, Silva JC, Meola J, Ferriani RA, Yoshimoto M, Santos SA, et al. Genomic alterations detected by comparative genomic hybridization in ovarian endometriomas. Braz J Med Biol Res (2010) 43(8):799-805. doi:10.1590/S0100-879X2010007500072

39. Taniguchi M, Takeuchi T, Nakatsuka R, Watanabe T, Sato K. Molecular process in acute liver injury and regeneration induced by carbon tetrachloride. Life Sci (2004) 75(13):1539-49. doi:10.1016/j.lfs.2004.02.030

40. Safadi R, Ohta M, Alvarez CE, Fiel MI, Bansal M, Mehal WZ, et al. Immune stimulation of hepatic fibrogenesis by CD8 cells and attenuation by trans- genic interleukin-10 from hepatocytes. Gastroenterology (2004) 127(3):870-82. doi:10.1053/j.gastro.2004.04.062

41. Shi Z, Wakil AE, Rockey DC. Strain-specific differences in mouse hepatic wound healing are mediated by divergent $\mathrm{T}$ helper cytokine responses. Proc Natl Acad Sci U S A (1997) 94(20):10663-8. doi:10.1073/pnas.94.20. 10663

42. Recknagel RO, Glende EA Jr, Dolak JA, Waller RL. Mechanisms of carbon tetrachloride toxicity. Pharmacol Ther (1989) 43(1):139-54. doi:10.1016/0163-7258(89)90050-8

43. Weber LW, Boll M, Stampfl A. Hepatotoxicity and mechanism of action of haloalkanes: carbon tetrachloride as a toxicological model. Crit Rev Toxicol (2003) 33(2):105-36. doi:10.1080/713611034

44. Racanelli V, Rehermann B. The liver as an immunological organ. Hepatology (2006) 43(2):S54-62. doi:10.1002/hep.21060

45. Abu-Amara M, Yang SY, Tapuria N, Fuller B, Davidson B, Seifalian A. Liver ischemia/reperfusion injury: processes in inflammatory networks - a review. Liver Transpl (2010) 16(9):1016-32. doi:10.1002/lt.22117

46. Zimmermann HW, Trautwein C, Tacke F. Functional role of monocytes and macrophages for the inflammatory response in acute liver injury. Front Physiol (2012) 3:56. doi:10.3389/fphys.2012.00056

47. Chung HK, Kim JT, Kim HW, Kwon M, Kim SY, Shong M, et al. GDF15 deficiency exacerbates chronic alcohol- and carbon tetrachloride-induced liver injury. Sci Rep (2017) 7(1):17238. doi:10.1038/s41598-017-17574-w

48. Panasiuk A, Prokopowicz D, Zak J, Wysocka J. Peripheral blood T, B, and NK cells in relation to histological hepatitis activity and fibrosis stage in chronic hepatitis C. Hepatogastroenterology (2003) 50(49):178-82.

49. Iorga A, Dara L, Kaplowitz N. Drug-induced liver injury: cascade of events leading to cell death, apoptosis or necrosis. Int J Mol Sci (2017) 18(5):1018. doi:10.3390/ijms18051018

50. Bak J, Je NK, Chung HY, Yokozawa T, Yoon S, Moon JO. Oligonol ameliorates $\mathrm{CCl}(4)$-induced liver injury in rats via the NF-kappa B and MAPK signaling pathways. Oxid Med Cell Longev (2016) 2016:3935841. doi:10.1155/2016/3935841

51. Luedde T, Schwabe RF. NF-kappaB in the liver - linking injury, fibrosis and hepatocellular carcinoma. Nat Rev Gastroenterol Hepatol (2011) 8(2):108-18. doi:10.1038/nrgastro.2010.213

Conflict of Interest Statement: The authors declare that the research was conducted in the absence of any commercial or financial relationships that could be construed as a potential conflict of interest.

Copyright (c) 2018 Lin, Sun, Jin, Lei, Liu, Hu, Wang, Shen and Wang. This is an open-access article distributed under the terms of the Creative Commons Attribution License (CC BY). The use, distribution or reproduction in other forums is permitted, provided the original author(s) and the copyright owner are credited and that the original publication in this journal is cited, in accordance with accepted academic practice. No use, distribution or reproduction is permitted which does not comply with these terms. 